Rev Biomed 2003; 14:131-142.

\title{
Identificación de factores de riesgo asociados con el manejo de residuos peligrosos biológicos infecciosos en trabajadores de hospitales de nivel III en la ciudad de México.
}

\section{Artículo Original}

Gustavo R. Valdovinos-Núñez.

Centro de Investigación en Ciencia Aplicada y Tecnología Avanzada (CICATA) Unidad Legaria, Instituto Politécnico Nacional, México, D.F., México.

\section{RESUMEN.}

Introducción. El objetivo de este estudio fue identificar el origen de los riesgos de trabajo del personal que maneja los residuos peligrosos biológicos infecciosos (RPBI) generados en tres departamentos, de unidades médicas de Nivel III del sector salud en la ciudad de México.

Material y Métodos. Se aplicaron encuestas a una muestra de trabajadores de cada uno de los siguientes departamentos: patología, laboratorio de análisis clínicos y laboratorio de banco de sangre. Se evaluó la compatibilidad entre: 1) el conocimiento de la norma NOM-087-ECOL-SSA1-2002 y 2) el apropiado desempeño de la tarea por parte del personal, asignando a los encuestados en cuatro categorías de riesgo. Para identificar diferencias entre los grupos de riesgo se aplicó la prueba ji cuadrada de bondad de ajuste para más de dos categorías corregida por continuidad de Yates, para identificar diferencias entre los grupos estudiados.

Resultados. El mayor porcentaje de trabajadores fue asignado al grupo de trabajadores en riesgo así como a su departamento. Esto destaca la falta de congruencia entre el conocimiento de la normatividad y la tarea correspondiente al proceso de trabajo, por los cual existe una divergencia muy amplia entre los aspectos teóricos legales y la ejecución real de la tarea.

Discusión. Se establece que, en general, el conocimiento de la normatividad es precario para los trabajadores de hospitales de nivel III en la ciudad de México y, en consecuencia, el trabajador no puede llevar a cabo la tarea en las condiciones de seguridad e higiene adecuadas para él y su departamento. Esto propicia que el trabajador ponga en grave riesgo su salud y la del departamento respectivo. Se recomienda implementar un programa de sistematización encaminado a identificar y fortalecer las debilidades inherentes al conocimiento de la normatividad y al perfil de los trabajadores que manejan RPBI con la finalidad de reducir y eventualmente eliminar los riesgos de trabajo en

Solicitud de sobretiros: M.C. Gustavo R. Valdovinos-Nuñez. Departamento de Apicultura, Facultad de Medicina Veterinaria y Zootecnia, Universidad Autónoma de Yucatán, Km. 15.5 Carr. Mérida-Xmatkuil, Apdo. Postal 4-116 Itzimná, C.P. 97100, Mérida, Yucatán, México. E-mail: rafng24o@prodigy.net.mx Recibido el 23/Octubre/2002. Aceptado para publicación el 8/Septiembre/2003. Este artículo está disponible en http://www.uady.mx/sitios/biomedic/revbiomed/pdf/rb031432.pdf 
GR Valdovinos-Núñez.

hospitales de nivel III de la ciudad de México.

(Rev Biomed 2003; 14:131-142)

Palabras clave: riesgo de trabajo, residuos peligrosos biológicos infecciosos, Salud Pública.

\section{SUMMARY.}

\section{Identification of risk factors associated with} the handling of hazardous biological infectious waste (HBIW) in employees of level III hospìtals in Mexico city.

Introduction. The objective of this study was to identify the origin of the labour risks of the personnel handling Hazardous Biological Infectious Waste (HBIW), generated in three departments of level III medical institutions of the health system in Mexico city.

Materials and Methods. The methodology consisted in designing and applying questionnaires to workers of the departments of pathology, clinical analysis laboratory, and blood bank laboratory of level III medical institutions. This allowed for an evaluation of the compatibility between 1) The knowledge of the regulation NOM-087-ECOLSSA1-2002 and 2) the appropriate performance of the personnel at different tasks related to the handling of HBIW.

A chi -square test of goodness of fit was applied for more than two categories and was followed by a Yate's correction for continuity, between groups in order to test the statistical significance.

Results. A lack of compatibility between knowledge of the regulation and tasks related with the process of work was evident. Therefore, there was a wide divergence between the legal theoretical aspects and the real performance of the task.

Discussion. It is established that, in general, the knowledge of the regulation is precarious. Therefore, the workers of level III hospitals in Mexico City may not be able to accomplish their tasks under the appropriate conditions of safety and hygiene. This situation makes the worker prone to higher risks as well as the respective department.
A systematic program is recommended, aimed at identifying and correcting the weak profile of the workers due to a lack of knowledge of the regulations on HBIW management. This will eventually lead to a reduction of the risks at work in level III hospitals, in Mexico City.

(Rev Biomed 2003; 14:131-142)

Key words: work risks, hazardous biological infectious wastes, Health System.

\section{INTRODUCCIÓN.}

Los residuos peligrosos generados por diferentes sectores de la producción ocupan un lugar trascendente en las enfermedades y accidentes laborales, en los impactos ambientales y en el deterioro de la salud pública (1).

El presente estudio considera a los residuos peligrosos en el sector de producción de servicios, específicamente los hospitales. El tipo de residuos peligrosos generados en estas unidades de servicio médico se conoce como Residuos Peligrosos Biológico Infecciosos (RPBI) $(2,3)$. Estos también son conocidos como desechos hospitalarios, desechos médicos regulados desechos de bolsa roja o desechos biomédicos $(4,5)$. Estos residuos son capaces de trasmitir enfermedades infecciosas, debido a que incluyen materiales contaminados con sangre o líquidos corporales (5).

En México, de acuerdo al Artículo 3 fracción XXXII de la Ley general del Equilibrio Ecológico y la Protección al Ambiente, 8a Edición 1993 y a la Norma NOM-052 ECOL-93 se define al RPBI como "aquel que contiene bacterias, virus u otros microorganismos con capacidad de causar infección o que contiene o puede contener toxinas producidas por microorganismos que causan efectos nocivos a seres vivos y al ambiente, que se generan en establecimientos de atención médica".

El marco legal mexicano de los RPBI está sustentado en la NOM-087 ECOL 1995, publicada el 7 de noviembre de 1995 y puesta en vigor el 7 de mayo de 1996. A principios del 2000, se expide como anteproyecto de modificaciones y se hace

\section{Revista Biomédica}




\section{Riesgos de trabajo por residuos peligrosos biológicos infecciosos.}

disponible en la Internet (6). Finalmente se publicó en el Diario Oficial de la Nación el 17 de febrero de 2003 como NOM-087-ECOL-SSA1-2002 y cuyos objetivos van encaminados a la clasificación de los RPBI y a su manejo. El campo de aplicación incluye a todos los establecimientos que generen RPBI y los prestadores de servicios a terceros (7). En un principio, se emitió como elemento regulatorio de la protección del medio ambiente, a través de la Secretaria de Medio Ambiente y Recursos Naturales (SEMARNAT). Actualmente tiene observancia también sobre la protección de la salud, por la debida participación de la Secretaría de Salud (SS).

Los centros hospitalarios que generan RPBI se clasifican, de acuerdo a la NOM-087-ECOLSSA1-2002, en 3 niveles. Los hospitales de nivel I son aquellos que tienen hasta 5 camas y laboratorios clínicos y bancos de sangre que realizan análisis de 1 a 50 muestras al día. Los de nivel II son aquellos que tienen hasta 60 camas y realizan de 51 a 200 análisis al día, tienen bioterios y generan de 25 a $100 \mathrm{~kg}$ de residuos al mes. Los hospitales de nivel III son aquellos que cuentan con más de 60 camas y con centros de producción e investigación experimental en enfermedades infecciosas, realizan análisis de más de 200 muestras al día y generan más de $100 \mathrm{~kg}$ de residuos al mes. Estas son las que generan el mayor volumen de RPBI y cuentan con servicios de cirugía, de laboratorio, de rayos $\mathrm{X}$ y, en ocasiones, de medicina nuclear. En México, la mayoría de estos centros hospitalarios pertenecen al sector público, en el Distrito Federal (D.F.) y área Metropolitana. Existen 1869 unidades médicas de primer nivel, 97 de segundo nivel y 77 de tercer nivel (8). De estas ultimas 9 corresponden al estado de México y 68 al D.F.

Actualmente, el Distrito Federal, considerado como un generador de residuos más grande que la provincia, cuenta con un total de 16,640 camas (8) que generan diariamente $107,328 \mathrm{~kg}$ de residuos hospitalarios, de los cuales $48,256 \mathrm{~kg}$ corresponden a los $\operatorname{RPBI}(9,10)$, cantidad relevante que hace pertinente su estudio. A partir de la década de los ochenta ha crecido la atención mundial respecto al manejo de RPBI, principalmente debido a los riesgos de propagación de enfermedades virales tales como la hepatitis B y C $(11,12)$ y el Síndrome de Inmunodeficiencia Adquirida (SIDA) (13). Estas enfermedades se pueden transmitir a través de residuos contaminados de secreción humana, que contuvieran los virus respectivos y cuyo manejo y disposición no fueran los apropiados para artículos tales como jeringas y agujas, por parte de los generadores (4). Así mismo una inadecuada disposición final de estos RPBI (2-4) puede ocasionar un impacto ambiental negativo.

Debido a que en México no existe suficiente información sobre los riesgos a los que están expuestos los trabajadores de hospitales de nivel III por el manejo de RPBIs, la realización de este estudio tiene como objetivo la identificación y evaluación de los riesgos de trabajo (transmisión de enfermedades infectocontagiosas) a los que se enfrenta este personal. Esto se realizó mediante el contraste entre el desempeño de la tarea en un proceso de trabajo efectuado in situ y el conocimiento de la norma NOM-087-ECOLSSA1-2002.

\section{MATERIALES Y MÉTODOS.}

Este estudio se llevó a cabo en 3 unidades médicas de nivel III ubicadas en la Ciudad de México: Hospital Regional Unidad Adolfo López Mateos del Instituto de Seguridad y Servicios Sociales de los Trabajadores del Estado (ISSSTE), Hospital Juárez de México Sección Norte de la SS y Hospital Regional Vicente Santos Guajardo (No. 72) del Instituto Mexicano del Seguro Social (IMSS).

La selección de estas instituciones y hospitales se llevó a cabo por las siguientes razones: pertenecen al sector público y generan el $37.2 \%$ de un total de $80095 \mathrm{~kg} /$ día de RPBIs producidos en el D.F (10). Las instituciones seleccionadas abarcan el $88.8 \%$ de las camas censables y atienden alrededor de diez millones de derechohabientes del D.F. (8). Tienen personal altamente calificado y 


\section{GR Valdovinos-Núñez.}

equipos de punta en las diversas especialidades médicas. Finalmente, el número de pacientes que acuden a estos hospitales es elevado porque además de atender ahí a los de la zona metropolitana, se atienden a los de las zonas conurbadas y del interior de la república, provocando que la tasa promedio de generación de RPBI sea considerable.

Además, se pudo observar que la carga de trabajo es excesiva por lo que puede haber condiciones que provoquen la insatisfacción y el mal desempeño de la tarea, fomentando los accidentes y riesgos de trabajo para los trabajadores y sus departamentos (9).

Dentro de las unidades médicas seleccionadas, se eligieron los departamentos de: patología, laboratorio de análisis clínicos y laboratorio de banco de sangre.

La elección de estos tres departamentos en cada hospital se realizó después de una inspección preliminar habiéndose identificado que:

a) Presentan altos volúmenes de generación de RPBI.

b) El manejo de éstos puede no realizarse en las condiciones de seguridad e higiene especificadas. Tales condiciones propician que el riesgo aumente, incluso a través de documentos que han sido sido manchados con sangre contaminada (14). En algunas de las secciones de estos departamentos es frecuente encontrar personal que durante el manejo de estos documentos suele ingerir bebidas y alimentos.

c) Son departamentos que dan servicio a otros dentro del mismo hospital y su buen funcionamiento es determinante para que los otros departamentos puedan desarrollar su tarea.

d) Existe en ellos el manejo de sustancias químicas que aumentan el grado de riesgo para el trabajador y el departamento.

e) Estos departamentos pueden presentar equipos e instalaciones insuficientes e inadecuadas.

El grupo de trabajadores encuestados correspondió a la totalidad de los que laboran en los turnos matutino y vespertino de los departamentos de patología y de banco de sangre.
Estos departamentos representaban menor número de personal en comparación al laboratorio de análisis clínicos en los diferentes hospitales. Para el caso de laboratorio de análisis clínicos el número de encuestados fue mayor por haberse encuestado personal tanto de los turnos matutino, vespertino, nocturno y de días festivos.

Para poder elaborar los instrumentos de medición (cuestionarios) se tuvieron que seguir las siguientes etapas (ver figura 1):

a) Mediante la observación y el recorrido de las áreas de estudio, se elaboraron los mapas de riesgo de los departamentos seleccionados identificándose las áreas de mayor riesgo, los puestos de trabajo y sus actividades correspondientes. Se contrastaron las actividades reales con las propuestas por el manual de procedimientos de cada departamento (en el caso de que éste existiera).

b) Se evaluaron los equipos de trabajo e instalaciones de cada departamento, considerando los elementos de seguridad, higiene y ergonomía.

c) Se diseñaron guías de observación para los diferentes procesos de trabajo, señalando las tareas de más riesgo. Para su llenado se hicieron entrevistas a trabajadores y jefes de departamento para conocer la mecánica de la tarea y los equipos de seguridad utilizados.

d) Se participó en el comité de bioseguridad de una de las unidades médicas para conocer el desarrollo de la tarea de otros departamentos interrelacionados con los seleccionados.

e) Finalmente, como producto de este sondeo se diseñaron los cuestionarios que se aplicaron.

Éstos se enfocaron a evaluar dos aspectos de los trabajadores de los departamentos estudiados: 1) El nivel de conocimiento de la NOM-087ECOL-SSA1-2002 y 2) el nivel de desempeño de la tarea en los procesos de trabajo. Este análisis muestra la relación que existe entre el conocimiento de la norma y el proceso de trabajo por cada uno de los trabajadores.

El cuestionario está formado por dos secciones: la primera la constituyen veintidós 
Riesgos de trabajo por residuos peligrosos biológicos infecciosos.

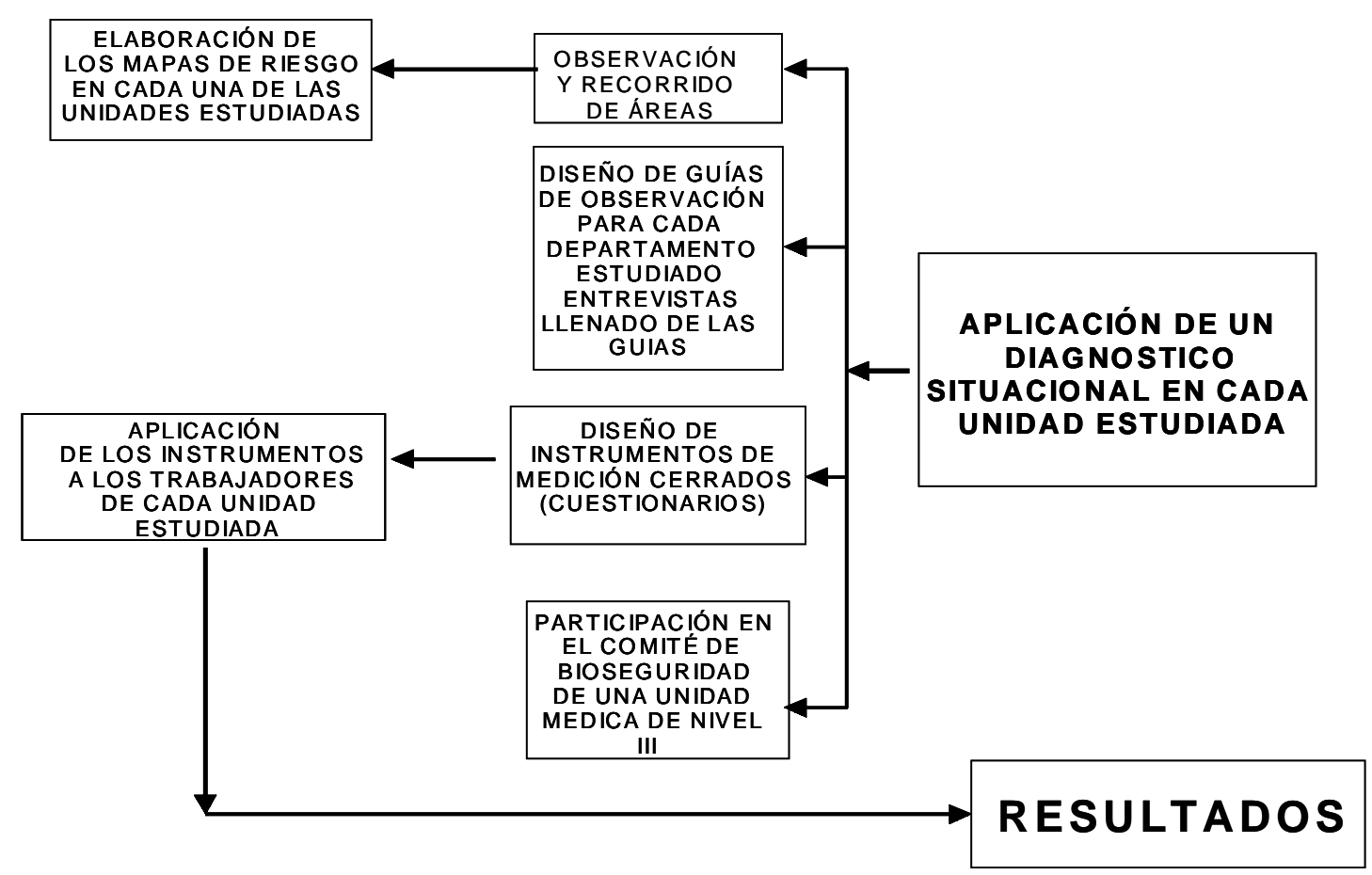

Figura 1.- Descripción esquemática de las etapas que se llevaron a cabo para la elaboración de los cuestionarios y su aplicación.

preguntas enfocadas al conocimiento de la norma NOM-087-ECOL-SSA1-2002, cuatro se refieren a la identificación de los residuos peligrosos y los RPBI, cinco a la clasificación y envasado de los RPBI, cuatro de las especificaciones del material de envasado, cuatro del manejo que deben tener los RPBI, los equipos de seguridad y los medios de transporte, tres de la disposición de los RPBI y dos de las condiciones de seguridad e higiene que deben existir en el medio laboral de los trabajadores. La primera sección del cuestionario es la misma para los tres departamentos encuestados. La segunda sección evaluó el desempeño de la tarea y consta de preguntas que identifican un adecuado manejo de los instrumentos y equipos de trabajo, los equipos de protección del trabajador, la coordinación en tareas compartidas por varios trabajadores, las acciones a tomar en caso de accidentes ocasionados en el desempeño de la tarea y de derramamientos de RPBI en áreas de transito, las instalaciones de los sistemas de drenaje, aireación, iluminación, etc. En esta sección se involucran todos los elementos reales que son inherentes al desarrollo de la tarea, desde la generación del residuo, el envasado, transporte interno, almacenamiento temporal y disposición final. A diferencia de la primera sección del cuestionario, esta segunda sección es específica para cada departamento estudiado; para patología son diecinueve preguntas, veintidós para laboratorio de análisis clínicos y quince para banco de sangre.

De esta forma el cuestionario pretende medir la correspondencia que debe existir entre la regulación y la tarea por parte del trabajador, cuánto conoce de la norma, y cómo esto se refleja en la realización de la tarea.

Si un trabajador conoce la regulación y lleva a cabo la tarea como lo dicta la misma y se cuenta con las condiciones de seguridad e higiene apropiadas, entonces estará fuera de riesgo. Si esto se aplica para el total de trabajadores, se espera entonces que todo el departamento esté fuera de riesgo (9).

De los cuestionarios aplicados se obtuvieron cuatro grupos de riesgo con base en el porcentaje de respuestas correctas. Estos grupos fueron los 
GR Valdovinos-Núñez.

Cuadro 1

Criterios de evaluación para el conocimiento de la norma 087 y del proceso de trabajo de acuerdo al porcentaje de preguntas respondidas satisfactoriamente por trabajadores de 3 hospitales de nivel III de la ciudad de México (6).

\begin{tabular}{|c|c|c|c|}
\hline $\begin{array}{l}\% \\
\text { de res- } \\
\text { puestas } \\
\text { correctas }\end{array}$ & $\begin{array}{l}\text { NORMATIVIDAD } \\
\text { NOM-087-ECOL-SSA1-2002 }\end{array}$ & PROCESO DE TRABAJO & CLASIFICACION \\
\hline $80-100$ & $\begin{array}{l}\text { Conoce perfectamente la } \\
\text { Normatividad independientemente } \\
\text { de la tarea que desempeñe o } \\
\text { desconoce algunos puntos del } \\
\text { marco jurídico y algunos de los } \\
\text { requisitos específicos en el } \\
\text { manejo de los RPBI. } \\
\text { El riesgo no existe para este } \\
\text { trabajador. Sin embargo, el riesgo } \\
\text { se transfiere a aquellos que hacen } \\
\text { la tarea de recolección y } \\
\text { disposición final por no poder } \\
\text { identificar a tiempo los RPBIs. }\end{array}$ & $\begin{array}{l}\text { Tiene la aptitud para la tarea y } \\
\text { conoce el riesgo inherente a ella, } \\
\text { además de que las instalaciones } \\
\text { y equipos de seguridad son } \\
\text { adecuados. Sin embargo, pueden } \\
\text { haber deficiencias en los recursos } \\
\text { materiales pero el trabajador toma } \\
\text { las precauciones necesarias para } \\
\text { evitar el riesgo de contraer } \\
\text { una enfermedad. }\end{array}$ & Trabajador fuera de riesgo \\
\hline $60-79$ & $\begin{array}{l}\text { Desconoce los conceptos del } \\
\text { marco jurídico, especificaciones } \\
\text { de envasado, y además los } \\
\text { requisitos de transporte interno } \\
\text { y almacenamiento temporal } \\
\text { (casos en los cuales se almacenan } \\
\text { los RPBIs dentro de las mismas } \\
\text { áreas de trabajo) }\end{array}$ & $\begin{array}{l}\text { Conoce la tarea y los riesgos } \\
\text { inherentes a ella. Los equipos de } \\
\text { seguridad personal y los } \\
\text { instrumentos de trabajo no son } \\
\text { adecuados y suficientes. Sin } \\
\text { embargo, las instalaciones } \\
\text { son las adecuadas. }\end{array}$ & Trabajador en riesgo \\
\hline $59-40$ & $\begin{array}{l}\text { Desconoce los requisitos básicos } \\
\text { de identificación y clasificación, } \\
\text { envasado, transporte interno y } \\
\text { almacenamiento temporal. No } \\
\text { tiene idea del tratamiento previo } \\
\text { que se les puede dar a los RPBIs } \\
\text { antes del desalojo del área. }\end{array}$ & $\begin{array}{l}\text { Conoce la tarea pero desconoce } \\
\text { los riesgos inherentes a ella. } \\
\text { Los equipos de seguridad e } \\
\text { instalaciones son insuficientes } \\
\text { e inadecuados. }\end{array}$ & $\begin{array}{l}\text { El trabajador se encuentra } \\
\text { en riesgo de trabajo, así } \\
\text { como los compañeros del } \\
\text { área correspondiente. }\end{array}$ \\
\hline $0-39$ & $\begin{array}{l}\text { Desconoce en su totalidad la } \\
\text { normatividad. }\end{array}$ & $\begin{array}{l}\text { No hay aptitud para el } \\
\text { desarrollo de la tarea y } \\
\text { desconoce sus riesgos. El perfil } \\
\text { del trabajador no corresponde } \\
\text { al puesto de trabajo. No } \\
\text { existen equipos ni instalaciones } \\
\text { adecuadas y suficientes. }\end{array}$ & $\begin{array}{l}\text { Está en alto grado de } \\
\text { riesgo, así como los } \\
\text { compañeros de área. Se } \\
\text { pueden presentar las } \\
\text { condiciones para una } \\
\text { probable contingencia } \\
\text { biológica o química. }\end{array}$ \\
\hline
\end{tabular}

siguientes: trabajador fuera de riesgo, trabajador en riesgo, trabajador y departamento en riesgo y riesgo de contingencia biológica (cuadro 1).

El levantamiento de las encuestas se realizó en el período 2000-2002 y se estableció la siguiente hipótesis:"si el trabajador conoce la Norma 087 y se tienen las condiciones de higiene y seguridad óptimas, debe existir un desempeño adecuado de la tarea dentro del proceso de trabajo que realiza y entonces no habrán riesgos de trabajo".
Para determinar si existieron diferencias en el número de trabajadores ubicados en cada categoría de riesgo y establecer la concordancia entre el conocimiento de la norma y el desempeño de la tarea dentro de cada laboratorio seleccionado, se aplicó la prueba ji-cuadrada de bondad de ajuste para más de dos categorías. En el caso de los criterios de riesgo con número de trabajadores igual a cero, no fueron considerados en las pruebas estadísticas y se aplicó la prueba de ji-cuadrada 
Riesgos de trabajo por residuos peligrosos biológicos infecciosos.

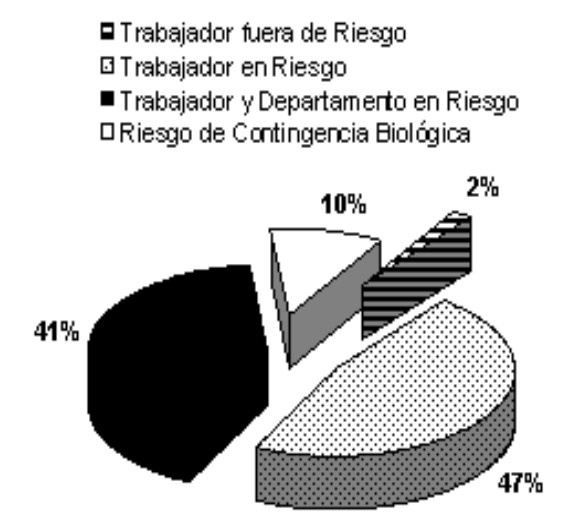

LABORATORIO DE PATOLOGIA (n= 44)

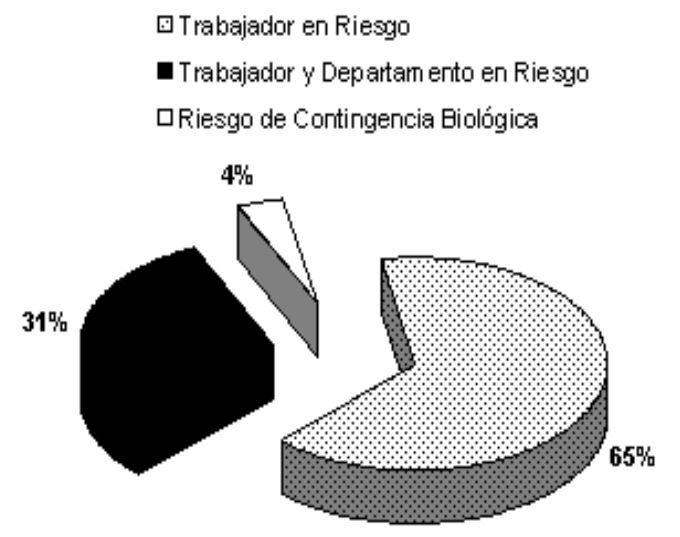

LABORATORIO DE BANCO DE SANGRE ( $n=54$ )

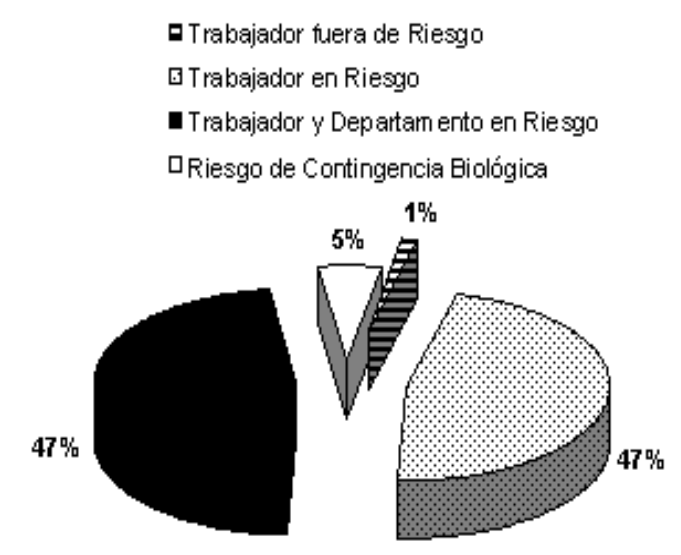

LABORATORIO DE ANÁLISIS CLÍNICOS (n= 125)

Figura 2.- Distribución de grupos de Riesgo entre el personal de los laboratorios de patología, banco de sangre y análisis clínicos en hospitales de nivel III de la ciudad de México, en función del conocimiento de la NOM-087-ECOL-SSA1-2002.

corregida por continuidad de Yates para dos categorías (15). El nivel de significancia empleado en éstas fue de 0.01 .

Con los resultados de la población en estudio y la aplicación de los criterios en el cuadro 1 se construyeron gráficas circulares en las que se muestra la proporción de la población ubicada en los distintos criterios de riesgo debido a sus niveles de conocimiento de la regulación y de la tarea.

\section{RESULTADOS.}

En este estudio se encuestaron a un total de 223 trabajadores. Cuarenta y cuatro (20\%) correspondieron al laboratorio de patología, 54 (24\%) al laboratorio del banco de sangre y 125 (56\%) al laboratorio de análisis clínicos. De acuerdo a las escalas de medición y al conocimiento de la norma, sólo dos $(0.8 \%)$ trabajadores estuvieron considerados fuera de riesgo para adquirir una enfermedad infecto-contagiosa, $115(51 \%)$ fueron considerados en riesgo, 93 (42\%) estuvieron en riesgo junto con su departamento y $13(6 \%)$ fueron considerados en riesgo de contingencia biológica. De acuerdo al desempeño de su tarea sólo un $(0.4 \%)$ trabajador fue considerado fuera de riesgo, $18(8 \%)$ se consideraron en riesgo, $58(26 \%)$ en riesgo junto con su departamento y $146(65 \%)$ en riesgo de contingencia biológica. Al comparar el conocimiento de la norma y el desempeño de la tarea por laboratorios, no se observó ninguna diferencia en el grupo que obtuvo el mayor porcentaje de respuestas correctas (80-100\%). ( $\mathrm{p}=0.4$ y 0.2 , respectivamente). Tampoco hubo diferencias entre el conocimiento de la norma y el 


\section{GR Valdovinos-Núñez.}

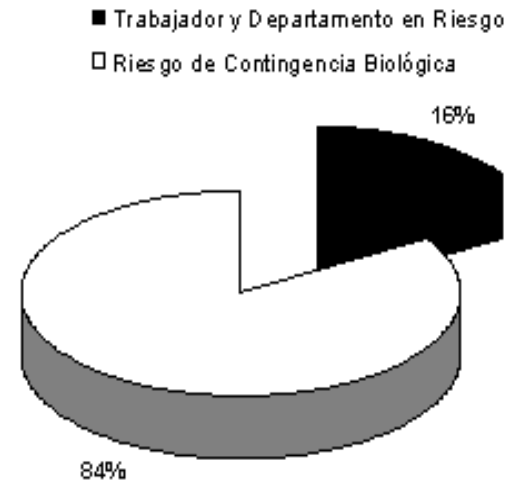

LABORATORIO DE PATOLOGIA (n= 44)

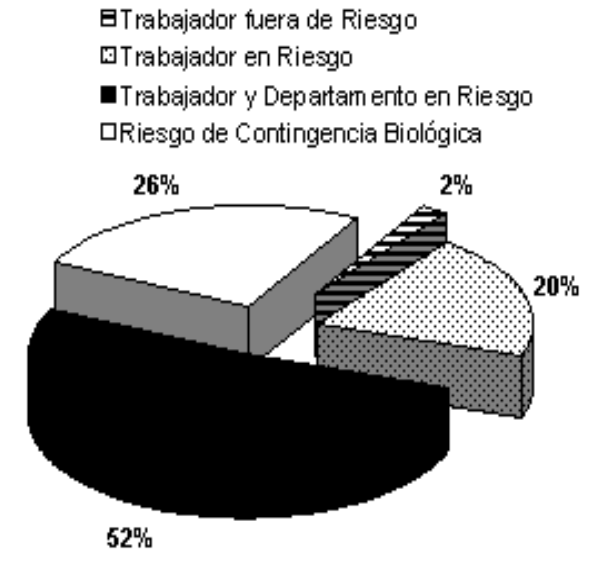

LABORATORIO DE BANCO DE SANGRE (n=54)

-Trabajador y Departam ento en Riesgo

पRiesgo de Contingencia Biológica

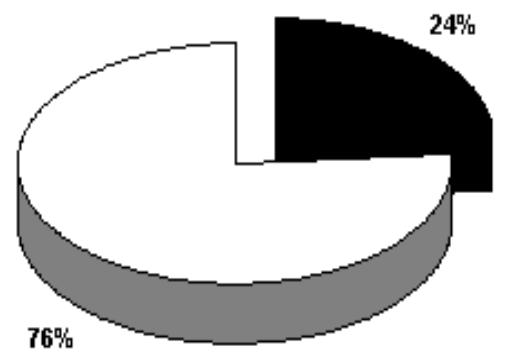

\section{LABORATORIO DE ANÁLISIS CLÍNICOS (n= 125)}

Figura 3.- Distribución de grupos de Riesgo entre el personal de los laboratorios de patología, banco de sangre y análisis clínicos en hospitales de nivel III de la ciudad de México, en función de la adecuada realización de la tarea en el proceso de manejo de RPBIs.

desempeño de la tarea $(\mathrm{p}=0.5)$.

El grupo de trabajadores considerados en riesgo (60-79\% de respuestas correctas) cerca o más de la mitad de los trabajadores conoce la norma, sin que exista diferencia significativa entre los laboratorios $(48 \%, 65 \%$ y $47 \%, \mathrm{p}=0.08)$. En relación al desempeño de la tarea, el porcentaje que tiene este conocimiento fue inferior $(16 \%, 20 \%$ y $0 \%$ ), siendo el laboratorio de análisis clínicos el de mayor riesgo $(\mathrm{p}=0.00005)$. Hubo una marcada discordancia entre el conocimiento de la norma y el desempeño de la tarea en los tres laboratorios $(\mathrm{p}<0.001)$.

El grupo de trabajadores en riesgo y cuyo departamento también está en riesgo (59-40\% de respuestas correctas) hubo un conocimiento de la norma de manera similar en los tres laboratorios Revista Biomédica analizados $(39 \%, 31 \%$ y $47 \%, \mathrm{p}=0.1)$ no habiendo diferencia significativa entre ellos. Sin embargo en la aplicación de la tarea, el porcentaje fue menor en el laboratorio de patología y en el de análisis clínicos (0\% y 24\%) siendo esta diferencia estadísticamente significativa $(\mathrm{p}<0.0001)$. En el laboratorio de banco de sangre hubo un mayor porcentaje de trabajadores que aplicaron sus conocimientos en el desempeño de sus tareas y un menor número de trabajadores que conocían la norma (52\% vs. $31 \%$ ), sin embargo esta diferencia no fue estadísticamente significativa ( $\mathrm{p}=0.0509)$.

En el grupo de trabajadores con menor porcentaje de calificación que están en riesgo de contingencia biológica (0-39\% de respuestas correctas) no hubo diferencia significativa en el conocimiento de la norma entre los tres laboratorios 


\section{Riesgos de trabajo por residuos peligrosos biológicos infecciosos.}

$(11 \%, 4 \%$ y $5 \%, \mathrm{p}=0.2)$, pero si la hubo en la aplicación de la tarea, siendo el laboratorio del banco de sangre el que menos se aplicó en el desempeño de sus tareas $(84 \%, 26 \%$ y $76 \%$, $\mathrm{p}<0.000001)$ figuras 2 y 3 .

De manera global la proporción de trabajadores fuera de riesgo, tanto por el conocimiento de la norma, como por el desempeño de sus tareas, fue mínima (1\%), la mayoría de los trabajadores está en riesgo, así como su departamento, de contraer una enfermedad infectocontagiosa tanto por desconocimiento de la norma (93\%) como por el inadecuado desempeño de sus tareas (37\%). Finalmente un $7 \%$ de los trabajadores está en condiciones de producir una contingencia biológica en su área al desconocer la norma y un $62 \%$ por el mal desempeño de sus tareas

\section{DISCUSIÓN.}

En el caso de que los encuestados conocieran la norma y la ejecución de la tarea se realizara en el marco de seguridad e higiene adecuados, se esperaría entonces que existiera un solo grupo, el cual estaría fuera de riesgo. Sin embargo, se pudo observar que en todos los laboratorios estudiados, el trabajador no conoce la norma y la ejecución de la tarea no se realiza en el marco de seguridad e higiene adecuados, lo que resultó en diferentes categorías de trabajo con diversos grados de riesgo. Se observó que para todos los departamentos existe un nivel bajo en la medición del conocimiento de la norma, dando como consecuencia que los trabajadores estén en riesgo, así como sus respectivos departamentos. Asimismo, fue notoria la situación de que ciertos trabajadores parecen conocer la norma pero la ejecución de la tarea la realizan en forma deficiente. Aun cuando el entorno de trabajo podría ser el adecuado para el trabajador, parece también haber un problema mayor de actitud en el desempeño de la misma.

En todos los departamentos se detectaron trabajadores que pueden poner en riesgo de contingencia biológica a su institución. Ésta ocurre por el desconocimiento del manejo y disposición de los residuos, que son similares para los departamentos en estudio. La falta de las condiciones de seguridad e higiene puede disparar dentro del mismo hospital la proliferación de virus tales como el de hepatitis B, el cual es capaz de sobrevivir a dosis infectantes sobre superficies contaminadas y secas por más de una semana (14, 16), y el virus de la hepatitis $C$ que se transmite por sangre infectada (16). De igual forma, el virus del SIDA, del que se han documentado accidentes ocupacionales de trabajadores de la salud por heridas de objetos punzocortantes, contaminados por sangre y fluidos de pacientes infectados. El virus es capaz de sobrevivir en material seco hasta por siete días y en materiales acuosos hasta por dos semanas a temperatura ambiente $(14,16)$. Asimismo, bacterias y otros microorganismos pueden permanecer vivos y virulentos en superficies e instrumentos inertes y cuya transmisión se puede dar, además, de un paciente a otro, de estos a los trabajadores e, incluso, entre estos últimos. Es importante también considerar que debido a que algunos microorganismos han desarrollado resistencia a los antibióticos debido a su exposición continua, actualmente por ser el hospital el lugar de mayor uso de antibióticos es el que presenta la flora bacteriana más resistente, de tal forma que si el trabajador ha sido infectado, la posibilidad de curarlo es muy baja (16).

Se ha enfatizado que la posibilidad de contaminación ambiental y riesgo para la comunidad es relativamente baja si los RPBI son debidamente eliminados $(3,13)$. Sin embargo, existe un riesgo mucho mayor para los trabajadores dentro de los hospitales si los residuos, en especial los punzocortantes, no son adecuadamente manejados durante el proceso de su eliminación $(2,14)$. En Estados Unidos, por ejemplo, se ha reportado que los trabajadores en contacto con RPBI pueden sufrir hasta un $46 \%$ de heridas, de las cuales $37 \%$ son resultado del manejo inadecuado de cristal, agujas y materiales de disección (17). Los riesgos de transmisión de enfermedades como la hepatitis $\mathrm{B}, \mathrm{C}$ y el SIDA por heridas con agujas infectadas 


\section{GR Valdovinos-Núñez.}

son evidentes (19-21), pero otras enfermedades bacterianas como la brucelosis (22), leptospirosis (23), malaria $(24,25)$ y tuberculosis (26- 28) pueden transmitirse por la misma vía.

Los departamentos estudiados mostraron la problemática de salud ocupacional de los hospitales de nivel III que puede derivar en diversos grados de riesgo que los trabajadores de este sector tienen para adquirir enfermedades infecciosas al no contar con la infraestructura indicada, los recursos materiales adecuados y suficientes, así como la capacitación teórica y operativa vigente. Las enfermedades infecciosas presentes en estos hospitales pueden ser transmitidas por vía sanguínea (como el virus del SIDA, hepatitis B, C), a través de rutas oral y fecal (como la salmonella, virus de hepatitis A), y a través de contacto directo (como el virus del herpes simple, la escabiasis, entre otras).

Estas enfermedades con frecuencia son adquiridas cuando se violan uno o más de los tres principios básicos de higiene en el control de infecciones, que son: el aseo personal (lavado de manos cuantas veces sea necesario), la vacunación de los trabajadores que están en contacto con los virus respectivos y la colocación inmediata de pacientes infectados en áreas apropiadas de aislamiento (29). Los riesgos de adquirir infecciones ocupacionales son parte inevitable del desempeño de los trabajadores del sector salud en su diario cuidado de pacientes, pudiendo causar que estos trabajadores enfermen y ocasionalmente mueran (29). Se requieren más estudios como éste que incluyan, además de los aspectos de prevención de riesgos para los trabajadores, los aspectos relacionados con los costos que involucran para la institución la adquisición de enfermedades infecciosas por parte del personal de este sector $(29,30)$.

A manera de conclusión, y dado el elevado grado de peligrosidad que podría derivar de una falta de conocimiento en la normatividad y el manejo de los RPBI, se sugiere que los hospitales propongan y desarrollen programas continuos de capacitación y evaluación para el personal que maneje RPBI y los cuales contemplen lo siguiente:

1.- Proporcionar la capacitación específica para los trabajadores que se encargan del cuidado de pacientes infectocontagiosos, en aquellas tareas cuya exposición a la transmisión de enfermedades por vía sanguínea a traves de punciones percutáneas, tales como en el reenfundado de agujas contaminadas y el manejo de punzocortantes quirúrgicos (21). Estos cursos deben ser extensivos incluso a estudiantes y residentes.

2.- Planear rotaciones del personal en diferentes puestos, para motivar su desempeño y lograr un cambio de actitud.

3.- Incentivar a aquellos trabajadores que tengan un buen desempeño en su actividad mediante bonificaciones y premios.

4.- Desarrollar un programa de sistematización para optimizar las diferentes etapas de la tarea en los procesos de trabajo, con la finalidad de minimizar: a) la contaminación por RPBI de residuos generados en las áreas de preparación de alimentos y administrativas debido a una inadecuada clasificación; b) los accidentes y riesgos de trabajo; c) gastos de almacenamiento para la empresa.

5.- Proponer alternativas de control en las diferentes fases del manejo de los RPBI, desde su generación hasta el almacenamiento temporal o disposición inmediata.

6.- Identificar las necesidades de capacitación específicas en aquellos aspectos que se consideren deficiencias (habilidades y actitudes) en el trabajador.

7.- Evaluar en forma continua los elementos de seguridad e higiene que están presentes en el desarrollo de la tarea en los procesos de trabajo.

8.- Evaluar el impacto del programa de sistematización en forma continua (por lo menos cada seis meses) y ajustarlo a las variaciones de la estructura laboral y de normatividad.

9.- Realizar un seguimiento y control de esta propuesta de sistematización por parte de las comisiones de bioseguridad, y/o quien la diseñó, para lograr la prevención de los riesgos de trabajo (9).

\section{Revista Biomédica}




\section{Riesgos de trabajo por residuos peligrosos biológicos infecciosos.}

En vista de que no existen muchos estudios que vayan enfocados al bienestar de este sector en materia de RPBI, se espera que el presente haga eco en este sector de servicios y contribuya al cumplimiento de las normatividades vigentes en materia laboral y ambiental, mejorando el medio ambiente laboral de estos centros de trabajo y elevando el costo-beneficio de el programa de prevención en la institución, al disminuir las incapacidades profesionales y los accidentes de trabajo (31). Así mismo, la institución, además de ofrecer un mejor servicio de salud a la comunidad, contribuirá a la disminución del impacto ambiental, elevando la calidad de la salud pública y fomentando el equilibrio biopsicosocial de los individuos (32).

\section{AGRADECIMIENTOS.}

Agradezco al Dr. Carlos Parrao, Jefe del Laboratorio de Análisis Clínicos y al Dr. Gustavo Acosta Altamirano, consulta externa y miembro de la Comisión de Bioseguridad del Hospital Juárez de México sección norte, de la Secretaria de Salud, al Dr. Luis Alcázar Álvarez, Jefe del departamento de Investigación y a la E.P. María Gloria Martínez Flores, Coordinadora de Enfermería del Hospital Regional Adolfo López Mateos del ISSSTE por el apoyo y ayuda brindados para la realización de este trabajo.

Gracias al Dr. José Javier Quezada Euán de la UADY por sus comentarios sobre el manuscrito.

\section{REFERENCIAS.}

1.- Turnberg WL, Frost F. Survey of occupational exposure of waste industry workers to infectious waste in Washington State. Am J Pub Health 1990; 80: 1262-64.

2.- Lee CC, Huffman GL, Nalesnik RP. Medical waste management. Environ Sci Technol 1991; 25: 360-3.

3.- Rutala WA, Weber DJ. Infectious waste. N Engl J Med 1991; 325: 578-82.

4.- Garcia RBS. Effective cost reduction strategies in the management of regulated medical waste. Am J Infect Control 1999; 27: 165-75.

5.- Cocchiarella L, Deitchman SD, Young DC. Report of the Council on Scientific Affairs: Biohazardous waste management : what the physicians needs to know. American Medical Association. Arch Fam Med 2000; 9:269.
6.- SEMARNAT. Anteproyecto de Modificaciones a la Norma Oficial Mexicana NOM-087-ECOL-2000. Protección ambiental-residuos peligrosos biológico-infecciososclasificación y especificaciones de manejo. 2000. Disponible en : http://www.adm.org.mx/normas/nom-087ecol-2000.html

7.- SEMARNAT-SSA. Norma Oficial Mexicana NOM-087ECOL-SSA1-2002, Protección ambiental -Salud Ambiental-Residuos peligrosos biológico-infecciososClasificación y especificaciones de manejo. Diario Oficial de la Federación 2003 Febrero 17; Sección 1:10-20.

8.- INEGI. GIIS. Boletín de Información Estadística No. 20. Recursos y Servicios.2000. Disponible en: http:// www.inegi.gob.mx/difusion/espanol/fdesinf.html

9.- Valdovinos-Nuñez GR. Propuesta de sistematización integral en el control de los residuos peligrosos biológico infecciosos generados en una unidad médica de nivel II en la ciudad de México (Tesis de Maestría ). México DF: Instituto Politécnico Nacional;1999.

10.- INE-SEMARNAT Dirección de Investigación sobre Sustancias Químicas y Riesgos Ecotoxicológicos. 2002. Disponible en: http://www.ine.gob.mx/dgicurg/sqre/ sustancias_amb.html\#top

11.- Booth JCL, Brown JL, Thomas HC. The management of chronic hepatitis C virus infection. Int J Gast Hepa 1995; 37: 449-54.

12.- Liang TJ, Reheman B, Seef LB, Hoofnagle J. Pathogenesis, natural history, treatment, and prevention of hepatitis C. Ann Inter Med 2000; 132: 296-305.

13.- Rutala, WA, Odette RL, Samsa, GP. Management of infectious waste by US hospitals. JAMA 1989; 262:163540.

14.- Fishman M, Mikolich DJ, Fort GG, Cataldo D. Medical records contaminated with dried blood: A quality issue. Am J Infect Control 1999; 27: 438-43.

15.- Zar JH. Biostatistical Analysis. $4^{\mathrm{a}}$ Ed. New Jersey :Prentice Hall;1999. p. 464-9.

16.- Moreno Sánchez F. Residuos peligrosos biológico infecciosos: Un punto de vista médico. Medicina InternaInfectología. Hospital ABC, Ciudad de México. La Jornada Ecológica. 1999. Disponible en: http://www.laneta.apc.org/ emis/jornada/may-jun99/medico.htm 


\section{GR Valdovinos-Núñez.}

17.- Sarri C, Eng E, Runyan C. Injuries among medical laboratory housekeeping staff: Incidence and worker perceptions. J Occup Med 1991; 33: 52-6.

18.- Seef LB, Buskell-Bales Z, Wrigth EC, Durako SJ, Alter HJ, Iber FL, et al. Long term mortality after transfusionassociated non-A, non-B hepatitis. N Engl J Med 1992; 327: 1906-11.

19.- Henderson DK, Fahey BJ, Willy M, Schmitt JM, Carey $\mathrm{K}$, Kosiol DE, et al. Risk for occupational transmission of Human Immunodeficiency Virus type 1(HVI-1) associated with clinical exposures. Am Coll Physicians 1990;113: 7406.

20.- Petrosillo N, Puro V, Jagger J, Ippólito G. The risks of occupational exposures and infection by human immunodeficiency virus, hepatitis B virus, and Hepatitis $\mathrm{C}$ virus in the dyalisis setting. Am J Infect Control 1995; 23: 278-85.

21.- Zuckerman AJ. Occupational exposure to hepatitis B virus and human immunodeficiency virus: A comparative risk analysis. Am J Infect Control 1995; $286-9$.

22.- Kiel FW, Khan MY. Brucellosis among hospital employees in Saudi Arabia. Infect Control Hosp Epidemiol 1993; 14:268-72.

23.- Vinetz JM. Leptospirosis. Infect Dis 2001; 14: 527-38.

24.- Haworth FLM, Cook GC. Needlestick malaria. Lancet 1995; 346: 1361.

25.- Varma AJ. Malaria acquired by accidental inoculation. Canad Med J 1982; 126:1419-20.

26.- Warren JP, Nairn DS, Robertson MH. Cold abscess after accidental BCG inoculation. Lancet 1984; 2: 289.

27.- Maloney SA, Pearson ML, Gordon MT, Del Castillo R, Boyle JF, Jarvis WR. Efficacy of control measures in preventing nosocomial transmission of multidrug resistant tuberculosis to patients and health care workers. Ann Intern Med 1995; 122:90-5.
28.- Sobel E, Sherertz RJ, Streed SA, Brown V, Bishop C, Rutala W, et al. HEPA Respirators and tuberculosis in hospitals workers. N Engl J Med 1994; 331:1658-60.

29.- Sepkowitz, KA. Ocupationally acquired infections in health care workers: Part II. Ann Intern Med 1996;125: 917-28.

30.- Pinkerton SD, Holtgrave DR, Pinkerton HJ, Milwaukee W. Cost-effectiveness of Chemoprophylaxis after occupational exposure to HIV. Arch Inter Med 1998; 158: $1470-1$

31.- Hagen DL, Al-Humaidi F, Blake MA. Infectious waste surveys in a Saudi Arabian hospital: An important quality improvement tool. Am J Infect Control 2001; 29: 198-202.

32.- Holtgrave DR, Crosby RA. Social capital, poverty, and income inequality as predictors of gonorrhoea, syphilis, Chlamydia and AIDS case rates in the United States. J Sex Health HIV 2003; 79: 62-4.

\section{Revista Biomédica}

